\title{
The role of devices in the closure of atrial septal defects in the oval fossa
}

\author{
Per G. Bjørnstad \\ Rikshospitalet, The National Hospital, Oslo, Norway
}

I ncreased knowledge, and modern developments in technology, have given birth to several techniques for interventional closure of atrial septal defects. During the last few years, at least five different devices have been the subject of clinical trials. These are various generations of the Sideris' buttoned device; the ASDOS [250]; the self-centring AngelWings [around 325]; CardioSEAL, the modified Clamshell device, [approaching 500]; and the nitinol Amplatzer plug [over 500]. The numbers in brackets refer, according to their manufacturers, to the world-wide implants in atrial septal defects or the oval foramen as of February 1998 for the four less-published devices. These numbers may not only mirror the general acceptance by cardiologists, but also the clinical compliance of the different devices. Only the buttoned device is well documented in the literature, ${ }^{1,2}$ although certainly a great part of the literature on the clamshell device ${ }^{3}$ might be considered relevant also for CardioSEAL. The other devices are presented in few, smaller series, ${ }^{4,5}$ or by their complications, ${ }^{6,7}$ representing serious setbacks in the implementation of a new method. Much of the present information is preliminary, and represents personal communications between investigators. It is now increasingly important to publish results with the use of different devices. I welcome, therefore, the articles in this issue of Cardiology in the Young. ${ }^{8,9}$

The optimal device should be easy to handle. Implantation should be feasible through a small introducer sheath. The device, when inserted, should be safe, retrievable, compatible with most atrial defects, and produce high rates of closure and

Correspondence to: Per G. B $j^{3 / 4 r n s t a d, ~ D e p t ~ o f ~ P a e d i a t r i c ~ C a r d i o l o g y ~}$ Rikshospitalet, N-0027 Oslo, Norway. Tel: +47-22 8690 92; Fax: +47-22 86 9101

Accepted for publication 11 March 1998 low complication rates. Serious complications should not occur, and closure with the device should never induce new lesions within the heart. Unfortunately, several devices do not presently satisfy these criteria.

Four of the devices use the same general concept: aiming to close the defect with a membrane on one or both sides of the atrial septum. Stability is achieved through a greater or lesser pressure of arms, constructed in different ways and arranged radially or circumferentially when open against the atrial wall. The Amplatzer is different. It is circular. It stents the hole, and sits like a peg within it, achieving stability by the pressure of the stenting component within the hole against its margins. This very concept may be its main advantage, resulting in high rates of closure and giving few complications. No rigid arms point towards neighbouring structures, avoiding any possibility of injury. The effect of the radial pressure against the atrial septum, and the potential annular distortion, however, is unknown. The somewhat bulky design probably does not matter, but the steel ends which protrude to either side may be a matter of concern regarding complete endothelialization.

In this issue, we publish articles from Melbourne ${ }^{8}$ and Toronto ${ }^{9}$ respectively, on interventional closure of atrial septal defects. They describe the use of two different devices, one from the stance of the performer, the other from that of the morphologist. Both contribute important knowledge.

In their series of patients, Wilkinson and $\mathrm{Goh}^{8}$ report complete closure of around 90\%, 1 month following implantation of the Amplatzer device. Their experience with displacement of one device, obviously the result of underestimation of the size of the defect, emphasizes that correct sizing is particularly critical for this device, demanding a specially designed sizing catheter. 
The careful selection of patients for closure will no doubt influence both failures and results. Threedimensional echocardiography, so beautifully displayed in the article by Maeno et al, 9 represents a means to better understanding of the specific anatomy of the septal deficiency, consequently improving the judgement of suitability for interventional closure. The article also discusses results subsequent to implantation, including malpositioning. Following the recommended approach will probably increase the rate of success, but we must realise that there are a number of possible sources of error in the present technology, and the authors themselves accurately describe the difficulty in differentiating between a true septal defect and echo drop-out. Quite a number of paediatric cardiologists will consider it difficult to use transoesophageal echo routinely in children, and some will wonder how the time required can be managed in the daily routine. Needless to say, interventions are preferable to the far more invasive cardiosurgical approach, provided of course that risks and results are comparable. One does not need clairvoyant capabilities to predict that closure of atrial septal defects increasingly will become the province of interventionists, analogous to what has happened in the treatment of valvar pulmonary stenosis and open arterial ducts. Recent articles from different parts of the world have documented that an operation for atrial septal defect has a low rate of complications, very little residual shunting, and an almost negligible mortality. Interventions to close atrial septal defects, self-evidently far less invasive than surgery, will still need to provide results comparable to such surgery if they are to compete. Our rates of complication, therefore, must be low even in the 'learning curve'. Serious complications or lesions must not occur but, alas, they have. Some devices certainly will show superior results compared to others with regards to closure, failures, and complications. The evidence from the Melbourne team, ${ }^{8}$ along with the findings of Masura et $\mathrm{al},{ }^{5}$ indicate that the Amplatzer might be such a device.
It is unlikely that all five devices will survive. Maybe the ultimate device has not yet been made. The devices now leave the era of investigational work and some will become freely available. It will be increasingly important, therefore, to maintain a sound balance between expectations and reality. We must not turn a blind eye to unforced errors, complications and poor results. Similarly, we must not perform interventions at any cost. There are certainly moments when ethics should prevail over techniques for the benefit of the patient.

\section{References}

1. Rao PS, Sideris EB, Hausdorf G, Rey C, Lloyd TR, Beekman RH, Worms AM, Bourlon F, Onorato E, Khalilullah M, Haddad J. International experience with secundum atrial septal defect occlusion by the buttoned device. Am Heart J 1994;128: 1022-1035.

2. Worms AM, Rey C, Bourlon F, Losay J, Marcon F, Godart F, Coullet JM. Experience francaise de la férmeture des communications interauriculaires de type ostium secundum par la prothèse boutonée de Sideris. Arch Mal Coeur 1996;89: 505-515.

3. Prieto LR, Foreman CK, Cheatham JP, Latson LA Intermediate-term outcome of transcatheter secundum atrial septal defect closure using the Bard Clamshell septal umbrella. Am J Cardıol 1996;78: 1310-1312.

4. Hausdorf G, Schneider M, Franzbach B, Kampmann C, Kargus K, Goeldner B. Transcatheter closure of secundum atrial septal defects with the atrial septal defect occlusion system: initıal experience in children. Heart 1996;75: 83-88.

5. Masura J, Gavora P, Formanek A, Hijazı ZM. Transcatheter closure of secundum atral septal defects using the new selfcentering Amplatzer Septal Occluder: Initial human experience. Cathet Cardtovasc Diagn 1997,42: 388-393.

6. Agarwal SK, Ghosh PK, Mittal PK. Fallure of devices used for closure of atrial septal defects: Mechanisms and management. J Thorac Cardiovasc Surg 1996;112: 21-26.

7. Bohm J, Bittigau K, K'hler F, Baumann G, Konertz W. Surgical removal of atrial septal defect occlusion systemdevices. Europ J Cardiothorac Surg 1997;12: 869-872.

8. Wilkinson JL, Goh TH: Early clinical experience with use of the 'ASO' (Amplatzer Septal Occluder) ASD device. Cardiol Young 1998; 8 (3): 295-302

9. Maeno YV, Benson LN, Boutın C: The impact of dynamic three-dimensional echocardiography in the assessment of atrial septal defect device occlusion. Cardiol Young 1998; 8 (3): $368-378$ 